\title{
The right and the wrong kind of reasons
}

Jan Gertken and Benjamin Kiesewetter

(Forthcoming in: Philosophy Compass)

In a number of recent philosophical debates, it has become common to distinguish between two kinds of normative reasons, often called the right kind of reasons (henceforth: RKR) and the wrong kind of reasons (henceforth: WKR). The distinction was first introduced in discussions of the so-called buck-passing account of value, which aims to analyze value properties in terms of reasons for pro-attitudes and has been argued to face the wrong kind of reasons problem. But nowadays it also gets applied in other philosophical contexts and to reasons for other responses than pro-attitudes, for example in recent debates about evidentialism and pragmatism about reasons for belief. While there seems to be wide agreement that there is a general and uniform distinction that applies to reasons for different responses, there is little agreement about the scope, relevance and nature of this distinction. Our aim in this article is to shed some light on this issue by surveying the RKR/WKR distinction as it has been drawn with respect to different responses, and by examining how it can be understood as a uniform distinction across different contexts. We start by considering reasons for pro-attitudes and emotions in the context of the buck-passing account of value $(\S 1)$. Subsequently we address the distinction that philosophers have drawn with respect to reasons for other attitudes, such as beliefs and intentions $(\S 2)$, as well as with respect to reasons for action $(\S 3)$. We discuss the similarities and differences between the ways in which philosophers have drawn the RKR/WKR distinction in these areas and offer different interpretations of the idea of a general, uniform distinction. The major upshot is that there is at least one interesting way of substantiating a general RKR/WKR distinction with respect to a broad range of attitudes as well as actions. We argue that this has important implications for the proper scope of buck-passing accounts and the status of the wrong kind of reasons problem $(\S 4)$.

\section{$\S 1$ Reasons for pro-attitudes and emotions}

According to an influential view that can be traced back at least to Brentano, what it is for some $\mathrm{X}$ to be good or valuable can be analyzed in terms of a normative relation that holds between $\mathrm{X}$ and certain positive or negative attitudes or emotions towards $\mathrm{X}$, such as e.g. 
admiration and disgust, desire and repulsion, or love and contempt. ${ }^{1}$ To keep things manageable, we will focus the discussion on pro-attitudes (in particular, on admiration and desire), and we will use "valuing" to cover both pro-attitudes and positive emotions directed towards an object. $^{2}$ For the purposes of illustration, consider the suggestion that X's being valuable consists in X's being such that ...

- it is rational or reasonable to value $\mathrm{X}$;

- it is correct to value $\mathrm{X}$;

- $\mathrm{X}$ should be valued, or ought to be valued;

- $\quad \mathrm{X}$ merits being valued or is worthy of being valued;

- $\mathrm{X}$ is a suitable or appropriate object of a relevant pro-attitude or emotion.

Analyses of this type are often referred to as fitting attitude analyses of value, ${ }^{3}$ which makes good sense if one uses "fitting" as an umbrella term for the different normative relations that views of this general kind have focused on. ${ }^{4}$ A relatively recent proposal for spelling out such an analysis, which has gained much attention in the philosophical literature, is the so-called buck-passing account of value (henceforth: BPV). According to the BPV, evaluative properties (or concepts) ${ }^{5}$ can be analyzed in terms of the normative reasons that count in favor of certain pro-attitudes towards the bearer of the property: ${ }^{6}$

\footnotetext{
${ }^{1}$ Cf. Brentano $(1889,11)$.

${ }^{2}$ As we use the term, valuing some object is thus to be distinguished from judging an object to be valuable.

${ }^{3}$ For historical and systematic overviews of fitting attitude analyses, see Rabinowicz and Rønnow-Rasmussen (2004) and Suikkanen (2009). Fitting attitude accounts that specifically focus on emotions are sometimes called "neo-sentimentalist analyses" of values; cf. D'Arms and Jacobson (2000a, 2000b).

${ }^{4}$ Note that this understanding of "fittingness" as an umbrella term differs from the use of that term in McHugh and Way (2016), who take "fittingness" to refer to a distinctive normative relation between an attitude and an object, which obtains when the attitude satisfies its internal standard of correctness (we discuss this notion of an internal standard below in $\S 2$ ). While we agree that this is a legitimate usage of that term, we are skeptical that it picks out the ordinary notion of "fitting", as McHugh and Way suppose. What is more, assuming that all analyses of values that philosophers nowadays classify as "fitting attitude analyses" attempt to analyze value in terms of a distinctive fittingness relation is a substantial and potentially controversial assumption, which needs to be established by an independent argument. In particular, we are not convinced that the buck-passing account of value (introduced below) must be understood as passing the buck twice, first from value to fittingness/correctness and then from fittingness/correctness to reasons. We want to allow for an understanding of the buck-passing account according to which it passes the buck directly from value to reasons, and is called a fitting attitude analysis only in the sense of belonging to a family of views that aim to analyze value in terms of some normative relation between an attitude and its object.

${ }^{5}$ For the purposes of this article, we assume that there are value properties, and we take the BPV to provide a metaphysical explanation of such properties rather than an analysis of evaluative concepts. Nothing important hinges on this: the relevant points could be rephrased in terms of concepts rather than properties.

${ }^{6}$ The expression "buck-passing account" comes from Scanlon (1998, 95-100). We have introduced the BPV as a specific form of fitting attitude analysis, which is how it is commonly understood. However, the expression "buck-passing account of value" can also be used in a more general way to cover all analyses of value that proceed in terms of normative reasons. Buck-passing accounts in this more general sense might refer to other
} 
$(\mathrm{BPV})^{*} \quad$ For it to be the case that $\mathrm{X}$ is valuable is for it to be the case that there are sufficient reasons for any (suitable) ${ }^{7}$ agent to value $\mathrm{X} .^{8}$

An analysis along these lines may be applied to general evaluative properties like being good, as well as to more specific properties such as being admirable. Accordingly, we might say that for it to be the case that some state of affairs is good is for it to be the case that there are sufficient reasons to desire that it obtains. Similarly, we might say that for it to be the case that some person is admirable is for it to be the case that there are sufficient reasons to admire her. The literature also contains a number of interesting proposals for extending the BPV to goodness-for (as in "vitamin C is good for you") and to attributive goodness (as in "Leon is a good hitman"). ${ }^{9}$

The BPV is a philosophically attractive hypothesis, because it promises to provide a reductive explanation of properties that many philosophers take to be in need of explanation (if not obscure), including the much-contested property of being good simpliciter. ${ }^{10}$ It offers a fitting attitude analysis that proceeds in terms of a notion that at least many philosophers believe to be indispensable anyway, and it explains several intuitively plausible necessary connections between reasons and value. Finally, it fits well with the increasingly popular reasons-first approach to normativity, which promises to provide an illuminating, unified account of normativity in terms of the notion of a reason. ${ }^{11}$

reasons than reasons for pro-attitudes, such as reasons for action, and hence they need not be fitting attitude analyses of value. Examples can be found in Scanlon (1998, 95-100) and Heuer (2011).

${ }^{7}$ Whether this restriction is necessary and what exactly it involves is a matter of substantial disagreement about reasons that seems irrelevant to the buck-passing project as a whole. For example, philosophers who accept that reasons (but not values) are subject to some kind of epistemic access constraint might characterize the suitable agent as being in possession of all relevant information, while others will not. For a discussion of epistemic constraints on reasons, see Kiesewetter (forthcoming).

${ }^{8}$ Some authors formulate the BPV as the claim that an object's property of being valuable can be reduced to the object's having other properties that provide reasons for valuing the object in question (cf. Scanlon 1998, 96-97). This amounts to restricting the relevant reasons for pro-attitudes to what Parfit (2011, App. A) calls "objectgiven reasons", and thus anticipates one prominent solution to the wrong kind of reasons problem, which we discuss below. We here want to formulate the BPV in a way that is neutral with respect to how it is supposed to deal with this problem.

${ }^{9}$ See esp. Rønnow-Rasmussen (2011), Rowland (2016), Schroeder (2010) and Skorupski (2007) for such proposals. Darwall (2002) can also be understood as defending a buck-passing account of what is good for an individual, although Darwall mostly formulates his claims in terms of what it is rational to desire for someone's sake, or in terms of what one ought to desire for someone's sake. For criticism of a buck-passing account of attributive goodness, see e.g. Gregory (2014).

${ }^{10}$ The locus classicus for skepticism about goodness simpliciter is Geach (1956). For a more recent version of such skepticism, see Thomson (2008, Ch. 1).

${ }^{11}$ Proponents of the reasons-first approach include Parfit (2011), Scanlon (1998), Skorupski (2010), and Schroeder (2007). For opposition to this view, see Thomson (2008, esp. Ch. 8). It is worth noting that the attractions of the BPV are not limited to the reasons-first approach. For authors who propose to analyze reasons in terms of another notion, such as the notion of rationality (Smith 1994, Ch. 5) or ought (Broome 2004), it can 
However, the BPV has also been argued to face a serious problem. To get a grip on this problem, let us first have a look at the kind of reasons that the buck-passer has in mind. The reasons for pro-attitudes and emotions that suit the purposes of the BPV are provided by those features that make the object of an attitude or emotion valuable. For example, it seems plausible to think that if some state of affairs involves pleasure, this is a reason to desire that this state of affairs obtains. Since it is likewise plausible to think that this feature contributes to making the state of affairs good, such a reason suits the purposes of explaining goodness in terms of reasons. Similarly, it seems plausible to think that a person's generosity provides a reason to admire her. Since it is likewise plausible to think that a person's generosity contributes to making her admirable, this is a reason that suits the purposes of explaining admirability in terms of reasons for admiration.

Let us call reasons for pro-attitudes that are provided by features that make the attitude's object valuable value-related reasons for pro-attitudes. ${ }^{12}$ As we have seen, such reasons are of the right kind to figure in the analysis of value suggested by the BPV. However, some philosophers think that there are also non-value-related reasons for proattitudes. To cite a much-discussed example from the literature, suppose that an evil demon threatens to torture you unless you admire it. ${ }^{13}$ This threat does not seem to contribute to the demon's admirability, but according to some philosophers, it nevertheless provides a reason for you to admire the demon. If such non-value-related reasons for pro-attitudes exist, they are of the wrong kind for the BPV. Indeed, if the demon's threat could provide you with sufficient reasons for admiring it, then $(\mathrm{BPV})^{*}$ is shown to be extensionally inadequate and in need of a qualification along the following lines:

$(\mathrm{BPV})^{* *}$ For it to be the case that $\mathrm{X}$ is valuable is for it to be the case that, putting aside reasons of the wrong kind, there are sufficient reasons for any (suitable) agent to value $\mathrm{X}$.

As it stands, however, this analysis is unsatisfactory. For all that has been said so far, WKR for pro-attitudes are reasons provided by features that do not make the attitude's object

\footnotetext{
be attractive to combine their view with the BPV in order to achieve a reductive analysis of both reasons and value in terms of the notion they believe to be more fundamental.

${ }^{12}$ By a "value-related reason" for a pro-attitude, we mean a reason related to the value of the object of the attitude. Thus, according to this terminology, a non-value-related reason might still be related to the value of the attitude rather than the object.

${ }^{13}$ For variants of this example, see Crisp (2000), Parfit (2011, App. A), and Rabinowicz and RønnowRasmussen (2004).
} 
valuable. Understood in this way, $(\mathrm{BPV})^{* *}$ is uninformative, if not viciously circular. ${ }^{14}$ To avoid circularity, buck-passers have to provide a criterion for distinguishing the wrong from the right kind of reasons that does not appeal to those value concepts or properties that the BPV is concerned with. This task is known as the wrong kind of reasons problem (henceforth: WKR problem). ${ }^{15}$

The literature contains a variety of suggestions for solving this problem. The most prominent proposals can be summarized (roughly) as follows:

- State-given vs. object-given reasons: WKR are provided by properties of the state of having the attitude (such as, for example, the benefits of admiring the demon), while RKR are provided by properties of the attitude's object (such as, for example, a person's generosity). ${ }^{16}$

- Derivative vs. non-derivative reasons: WKR are instrumental or derivative reasons for attitudes, while RKR are not. Derivative reasons are, roughly speaking, reasons for responses that one has because that response is conducive to something else one has reason to do or want. For example, one has reason to admire the demon because doing so is conducive to avoiding pain and one has reason to avoid pain. But if a person's generosity provides one with a reason to admire that person, this is not because admiring the person is conducive to something else one has reason to do or want. ${ }^{17}$

- Consequence-dependent vs. consequence-independent reasons: WKR depend on the benefits ${ }^{18}$ or, more generally, consequences ${ }^{19}$ of the attitude. In contrast, RKR are provided by features that would also provide reasons in the absence of these benefits, or independently of any consequences. For example, one has reason to admire the demon only because doing so brings it about that one avoids torture, while one has reason to admire a generous person independently of any consequences of admiring her.

\footnotetext{
${ }^{14}$ Rabinowicz and Rønnow-Rasmussen $(2006,119-20)$ suggest that the circularity at issue need not be vicious. We cannot here discuss the adequacy conditions for conceptual analyses and metaphysical reductions, but we will assume that no matter whether the BPV is to be understood as a conceptual or as a metaphysical claim, it will at least be significantly more informative if it avoids the circularity in question.

${ }^{15}$ The terminology was introduced in Rabinowicz and Rønnow-Rasmussen (2004). A similar problem, called the conflation problem, was pointed out before in D'Arms and Jacobson (2000a).

${ }^{16}$ See esp. Parfit (2001; 2011, App. A) and Piller (2006). Critical discussions include Rabinowicz and RønnowRasmussen (2004, 405-8; 2006), Olson (2004), Hieronymi (2005, 441-43), Lang (2008) and Schroeder (2012 and 2013). As mentioned above (in note 8), the proposal to identify RKR with object-given reasons is already implicit in some formulations of the BPV, such as Scanlon's $(1998,96)$, according to which an object's property of being valuable can be reduced to the object's having other properties that provide reasons for responding to it in certain ways.

${ }^{17}$ See Stratton-Lake (2005) and Suikkanen (2009). For criticism, see Lang (2008).

${ }^{18}$ See Lang (2008). For criticism, see Olson (2009).

${ }^{19}$ See Rowland (2013) and Samuelsson (2013).
} 
- Correctness-independent vs. correctness-related reasons: WKR are independent of the correctness of the relevant pro-attitude. By contrast, RKR are essentially related to the correctness of the pro-attitude, e.g. by suggesting that the attitude meets its internal standard of correctness. ${ }^{20}$ For example, the fact that a person is generous suggests that admiring this person would be correct, while the fact that a demon has threatened you with torture unless you admire it does not suggest that admiring the demon would be correct.

- Idiosyncratic vs. shared reasons: WKR with respect to some activity (understood in a wide sense that includes admiring or desiring) are not necessarily shared by others engaged in the same activity, at least not because they are engaged in this activity. By contrast, RKR are the reasons that are necessarily shared by everyone engaged in the relevant activity because they are engaged in this activity. ${ }^{21}$ For example, everyone engaged in the activity of admiring has, because they are engaged in this activity, reason to admire generous persons. But pain-free beings engaged in the activity of admiration would not have reason to admire the demon, and even if everyone engaged in the activity of admiration had such a reason, they would not have this reason because they are engaged in this activity.

Standard objections against solutions to the WKR problem are that they are extensionally inadequate and that they turn out to rely on the notion of value that the BPV aims to analyze. Although we cannot discuss these proposals here in any more detail, it is safe to say that none has so far gained wide acceptance.

A number of philosophers deny the existence of non-value-related reasons for proattitudes. According to such WKR Skepticism, the demon's threat does not provide a reason for admiring it; rather, it provides a reason to want or to try to bring it about that one admires it. More generally, what WKR proponents take to be non-value-related reasons for proattitudes, WKR skeptics take to be value-related reasons to want oneself to have the proattitude or practical reasons to (try to) bring this pro-attitude about. ${ }^{22}$

One of the most prominent arguments for WKR Skepticism is that non-value-related reasons for pro-attitudes are not capable of guiding the responses they are supposed to be reasons for. In Raz's terms, they do not satisfy the "normative/explanatory nexus", according

\footnotetext{
${ }^{20}$ See e.g. Danielsson and Olson (2007) and Sharadin (2015). For discussion, see Lang (2008) and RønnowRasmussen $(2011,40-42)$. We say more about the notion of an internal standard of correctness in $\S 2$.

${ }^{21}$ See Schroeder $(2007$, Ch. 7; 2010). For objections, see Sharadin $(2015, \S 2)$.

22 See e.g. Gibbard (1990, 37); Parfit (2011, App. A), Skorupski (2007), and Way (2012).
} 
to which "if that $\mathrm{R}$ is a reason to $\phi$ then it must be possible that people $\phi$ for the reason that R". ${ }^{23}$ For example, it seems that you cannot admire a demon for the reason that you would be tortured unless you admire it - all that you can do for this reason is to want or to try to bring it about (perhaps by visiting a hypnotist or taking other external measures) that you admire the demon. If this is correct, then non-value-related reasons for pro-attitudes might be ruled out on the assumption that the normative/explanatory nexus holds true. ${ }^{24}$

WKR Skepticism significantly changes the dialectic in the debate about the BPV, for it seems to dissolve the WKR problem. Recall that this problem consists in the fact that candidates for WKR are potential counterexamples to unqualified versions of the BPV, which need to be excluded from the analysis in a way that does not rely on the notion of value. If there are no WKR to begin with, this problem simply does not exist. For example, if incentives for admiring the demon do not provide reasons to admire the demon (but only reasons to want or to try to bring it about that one admires it), then such incentives provide no counterexample to the claim that for a person to be admirable is for it to be the case that there are sufficient reasons to admire her. No WKR problem without $\mathrm{WKR}^{25}$

So far, we have seen that the notion of a WKR has a well-defined meaning as a nonvalue-related reason for a pro-attitude, which is of the wrong kind to figure in an analysis of value along the lines of the BPV. We will now turn to other contexts in which philosophers have drawn a RKR/WKR distinction.

\section{$\S 2$ Reasons for other attitudes}

It is relatively uncontroversial that there are truth-related reasons for belief (often called epistemic reasons), which are provided by evidence that the belief in question is true. Some philosophers, however, think that there are also non-truth-related reasons for belief (often called pragmatic reasons), which are provided e.g. by the benefits of having the belief. ${ }^{26} \mathrm{~A}$ classical example is Pascal's Wager, according to which reason requires us to believe in God

\footnotetext{
${ }^{23} \operatorname{Raz}(2011,27)$. See also Williams $(1979,102)$.

${ }^{24}$ Arguments along these lines can be found e.g. in Kelly (2002, 172-81), Parfit (2011, App. A), Persson (2007, 4-9) and Rowland (2015). For discussions, see Hieronymi (2005, 440-43), Louise (2009) and Way (2012, 493). For further arguments for WKR Skepticism, see e.g. Parfit (2011, App. A), Skorupski (2007), and Way (2012). For arguments against WKR Skepticism, see Rabinowicz and Rønnow-Rasmussen (2004, 412-13) and Howard (2016).

${ }^{25}$ It is sometimes argued that WKR Skepticism only shifts the problem, since WKR skeptics face the resulting problem of having to explain, without relying on value notions, what makes something a reason for e.g. wanting to have a certain attitude rather than a reason for having the attitude in question (see e.g. Rabinowicz and Rønnow-Rasmussen 2004, 413). However, if it is legitimate to demand a fundamental explanation of what makes something a reason for one response rather than another in the first place, then proponents of the BPV need to provide such an explanation (without relying on value notions) even if there are WKR and even if the WKR problem has been solved. So if there is a problem, it is independent of the WKR problem.

${ }^{26}$ The locus classicus is James (1896). A more recent advocate of this view is Reisner (2009).
} 
because doing so has infinite expected utility. The expected utility of believing in God provides no evidence for God's existence and thus cannot provide a truth-related reason for that belief. If it provides a reason for belief, as Pascal seems to assume, this would be a nontruth-related reason.

It is also relatively uncontroversial that there are action-related reasons for intentions, which are reasons for intentions that are provided by features of the intended action. For example, that going to the movies will be fun is an action-related reason to intend to go to the movies, because it is provided by a feature of the action of going to the movies. Some philosophers think that there are also non-action-related reasons for intention. A famous example is Kavka's toxin puzzle, in which an eccentric billionaire offers you a large reward for intending to drink a glass of toxin, independently of whether you actually drink it or not. ${ }^{27}$ If the billionaire's offer provides you with a reason for intending to drink the toxin, this would be a non-action-related reason, for it is not provided by any feature of the action of drinking the toxin.

Intuitively, non-truth-related reasons for beliefs, non-action-related reasons for intentions, and non-value-related reasons for pro-attitudes resemble each other. It is therefore natural to assume that these reasons are members of a common general kind. We will call reasons of this kind non-standard reasons. Correspondingly, it seems plausible that valuerelated reasons for pro-attitudes, truth-related reasons for beliefs, and action-related reasons for intentions are members of a common kind as well, which we will call standard reasons. ${ }^{28}$

Schroeder has helpfully suggested a number of earmarks of typical standard and nonstandard reasons, which can be used to identify members of both kinds without a fully developed philosophical account. Firstly, there is a motivational asymmetry between standard and non-standard reasons: it seems particularly difficult, if not impossible, to admire a demon on the basis of a threat of torture, and the same seems to be true for believing or intending something for non-standard reasons. Typical standard reasons do not seem subject to this difficulty. Secondly, there is at least one important dimension of rationality that is unaffected by non-standard reasons, but affected by standard reasons. For example, the rationality of belief is typically assessed only in terms of evidence and not in terms of pragmatic reasons for

\footnotetext{
${ }^{27}$ See Kavka (1983).

${ }^{28}$ We borrow this terminology from Raz (2011, Ch. 3), who uses it to distinguish reasons that satisfy the normative/explanatory nexus from those that do not. Although we agree that non-standard reasons do not satisfy this nexus, we use the term "standard reason" in a less committal sense to refer to the common kind of reasons of which e.g. truth-related reasons for beliefs, value-related reasons for pro-attitudes and action-related reasons for intentions are members. By calling the other reasons "non-standard", we do not mean to suggest that such reasons are in any sense unusual, not normal or odd.
} 
belief. Thirdly, in contrast to standard reasons, non-standard reasons seem to be irrelevant to the correctness of the response they count in favor of. ${ }^{29}$

The idea of a uniform distinction between standard and non-standard reasons is independent of the WKR problem for the BPV, which is why we have so far avoided using the RKR/WKR terminology to express this idea. However, an increasing number of philosophers call non-standard reasons "reasons of the wrong kind", and some even speak of a general WKR problem that concerns non-standard reasons not only for pro-attitudes, but also for beliefs and intentions. ${ }^{30}$ It is not immediately obvious, however, in which sense nonstandard reasons for beliefs or intentions can be said to be "of the wrong kind" and what a more general WKR problem with respect to such reasons would consist in. In what follows, we will briefly present two different answers to this question. ${ }^{31}$

One possible interpretation is that "WKR" is simply used as a (slightly misleading) label for what we have called non-standard reasons. ${ }^{32}$ This terminological practice might have been adopted on the background assumption that all non-standard reasons are of the wrong kind to be followed directly, or to bear on the rationality or the correctness of a response, or simply on the assumption that they are in some sense of the same general kind as those reasons for pro-attitudes that are of the wrong kind for the BPV. On this interpretation, a general WKR problem might then be taken to consist in the challenge of providing a philosophical account of the distinction between standard and non-standard reasons, i.e. an account that explains why there are these two different kinds of reasons, and why they (typically) have the aforementioned earmarks. ${ }^{33}$ Developing such an account seems like a

\footnotetext{
${ }^{29}$ See Schroeder (2012, 458-61). See Rabinowicz and Rønnow-Rasmussen (2012b) and Hieronymi (2013) for a critical discussion of the status of these earmarks.

${ }^{30}$ Examples include Hieronymi (2005, 437-38), Jacobson (2013), Reisner (2009), Schroeder (2012, 461), Sharadin $(2015,373)$, and Way $(2012,490-92)$.

${ }^{31}$ There are more. For example, D'Arms and Jacobson (2014) argue that besides the theoretical problem for buck-passing accounts, non-standard reasons pose a serious epistemic problem in many real life situations, namely to figure out whether or not a given reason for or against an attitude (e.g. a reason against being amused about a certain joke) bears on whether its object merits the attitude (e.g. on whether a joke is funny).

${ }^{32}$ Compare Schroeder $(2012,466)$ : "the 'right-kind'/"wrong-kind' distinction was just a catch-all label designed to cover an important class of differences that arise in a variety of domains."

${ }^{33}$ Both Hieronymi $(2005,437-38$ and 453-55) and Schroeder $(2012,461)$ seem to conceive of the WKR problem in this way. Hieronymi's account, according to which RKR for an attitude are those considerations that "bear on a question the settling of which amounts to forming the attitude" (449), is not meant to solve the WKR problem for any sort of buck-passing account (cf. 2005, 455-56). Some passages in Hieronymi (2005) suggest that she takes non-standard reasons for attitudes to be WKR because they are of the wrong kind to provide "real" reasons for those attitudes, and that the WKR problem "lies in saying why the [non-standard] reasons are not 'really' reasons for the attitude in question" (441-2). It should be noted that this understanding is not only significantly different but logically inconsistent with the understanding of those who think that WKR pose a problem for the BPV: while the former entails WKR Skepticism, the latter presupposes the existence of WKR.
} 
general desideratum rather than a specific problem for any particular theory of reasons or values, such as the BPV. ${ }^{34}$

If we conceive of the WKR problem in this way, we should note two points. Firstly, the attempt to account for the distinction between standard and non-standard reasons is not subject to those particular constraints that restrict solutions to the WKR problem for the BPV. Unless one wants one's account to also provide a solution to this WKR problem, one is free to rely on evaluative notions when distinguishing standard from non-standard reasons. Secondly, while the WKR problem for the BPV is dissolved if WKR do not exist, skepticism about non-standard reasons does not as such evade the general challenge of providing a philosophical account of the distinction between standard reasons and those kinds of considerations that other philosophers take to be non-standard reasons. ${ }^{35}$ Of course, if nonstandard reasons for attitudes are really only reasons for wanting to have these attitudes or reasons to (try to) bring these attitudes about, then, strictly speaking, there is no subject matter for an explanatory account of non-standard reasons. But this still leaves in place the task of explaining why there are two very different sorts of reasons, one of which is easily misconstrued as reasons for pro-attitudes, emotions, beliefs and intentions, even though these reasons are really reasons for something else.

An alternative way to understand the practice of calling non-standard reasons "reasons of the wrong kind" emerges when we consider those reasons in light of a further-reaching reductive project than the BPV. The view that we have in mind aims to use the notion of a reason to explain all kinds of internal standards for attitudes. To understand this idea, consider again a pro-attitude such as admiration. Admiration plausibly has an internal standard of assessment - a standard that is met when the object of the admiration is admirable, and not met when it is not admirable. This standard is internal to the attitude of

\footnotetext{
${ }^{34}$ Note that merely listing those earmarks that characterize the standard/non-standard distinction does not yet amount to a philosophical account of this distinction. First, the earmarks are not meant to provide (individually or jointly) necessary or (individually or jointly) sufficient conditions for reasons to qualify as standard or nonstandard. Rather, they are to be understood as characterizing paradigmatic instances of either category, and just as the fact that some animal is a bird only provides defeasible evidence that this animal can fly, the earmarks also merely provide defeasible evidence that some reason is a standard or a non-standard reason. It is thus an open question, to be settled by further theoretical investigation, whether the earmarks (or some of them) apply to all members of those kinds that are defined by reference to the respective paradigm cases. Second, whereas a solution to the WKR problem for the BPV merely needs to correctly determine the extension of "reasons of the wrong kind" in a non-circular way, an account of standard and non-standard reasons is also meant to be explanatory. Thus, even if it turned out that one could formulate necessary and sufficient conditions for a reason to be a standard or non-standard reason by reference to the aforementioned earmarks, such a view would not yet in itself suffice to explain why there are two different kinds of reasons for attitudes with very different characteristics.

${ }^{35}$ See also Hieronymi $(2005,442)$ and Schroeder $(2012,461)$.
} 
admiration in the specific sense that it applies to the attitude because it is the kind of attitude that it is. ${ }^{36}$

A natural way to express the idea that an attitude meets its internal standard is by saying that the attitude's object merits the attitude and is worthy of it, or, referring to the inverse relation, by saying that the attitude in question is an appropriate, fitting or correct response to the respective object. ${ }^{37}$ Note, however, that the use of at least some of these expressions is not restricted to expressing the idea that an attitude's internal standard is met. Perhaps it can be morally inappropriate to be amused about something funny, and blaming a person might be said to be an unfitting response to someone's blameworthy action if doing so has unwanted consequences. ${ }^{38}$ In these cases, the relevant expressions are used with regard to standards that are not internal, since they do not apply to the relevant attitudes because they are the kind of attitudes they are. In what follows, our use of these terms is restricted to expressing the satisfaction of internal standards, and we will follow Schroeder, Thomson and others in using "correctness" as the general term for the property that an attitude has when it meets its internal standard. ${ }^{39}$

Many pro-attitudes and emotions are plausibly subject to internal standards. For example, desire can be said to be appropriate or correct when its object is desirable, amusement when its object is funny, and fear when its object is dangerous. On the face of it, being worthy of a response or being a correct or appropriate response look like normative properties that philosophers sympathetic to the reasons-first approach should not be happy with taking for granted. Schroeder, at any rate, is explicit that since "correctness is clearly a normative property", it "should be analyzable in terms of reasons". 40 This leads him to accept a buck-passing account of correctness (henceforth: BPC), along the following lines:

\footnotetext{
${ }^{36}$ Internal standards of attitudes or practices are sometimes claimed to be constitutive for them. Accordingly, what makes an attitude an instance of e.g. admiration is, in part, the fact that it is subject to a standard of assessment according to which the attitude is correct only if its object is admirable. See e.g. Sharadin $(2015,386)$. ${ }^{37} \mathrm{Cf}$. McHugh and Way $(2016,583)$, who prefer the term "fitting." Note again that this specific use of "fitting" differs from its use as an umbrella term for all analyses of value that proceed in terms of one or another normative relation between an attitude and its object (see note 4). In order to avoid confusion between these different notions, we mostly avoid the term "fitting."

${ }^{38}$ See e.g. D'Arms and Jacobson (2000b).

${ }^{39}$ See Schroeder $(2007$, Ch. 7; 2010; 2012) and Thomson $(2008$, Ch. 7). It should be noted that this use of "correctness" is at least to some degree stipulative. We suggest regarding it as a substantial and open question whether the property that a belief has when it satisfies its internal standard is the property of correctness in the ordinary sense, in which correct and true beliefs are co-extensional (as McHugh and Way $[2016,584]$ among others assume). On the face of it, the set of propositions that are credible or worthy of belief does not seem to be co-extensional with the set of true propositions.

${ }^{40}$ Schroeder $(2007,134)$.
} 
(BPC)* For it to be the case that $\phi$-ing is correct is for it to be the case that there are sufficient reasons for any (suitable) agent to $\phi .^{41}$

Accordingly, for it to be correct to fear some spider, is for it to be the case that there are sufficient reasons to fear the spider, and for it to be correct to blame some person is for it to be the case that there are sufficient reasons to blame her, etc. But note that if there are nonstandard reasons for fear or blame, then these reasons are WKR for the BPC and consequently, the BPC faces a WKR problem of the very same structure as the BPV.

Similar points seem to apply to beliefs, and presumably to intentions as well. Beliefs have an internal standard of correctness or appropriateness (perhaps one that corresponds to what is "credible" or "worthy of belief"). ${ }^{42}$ The BPC analyzes such properties in terms of reasons for belief. But if Pascalian considerations provide reasons for belief, these reasons are of the wrong kind for such an analysis, since the correctness of a belief is independent of its utility. Less obviously, intentions may be thought to have an internal standard of correctness as well (perhaps one that corresponds to the "choiceworthiness" of an action), which the BPC analyzes in terms of reasons. If toxin puzzle considerations provide reasons for intentions, however, they are WKR for the BPC, for such reasons do not bear on the choiceworthiness of the intended actions.

To generalize: the BPC is committed to analyzing an attitude's correctness in terms of the reasons for (and against) that attitude. But an attitude's correctness is unaffected by nonstandard reasons for this attitude. Non-standard reasons for attitudes with internal standards are thus WKR for the BPC and give rise to a WKR problem for it.

Considered from the angle of someone who is sympathetic to the BPC, the WKR problem for the BPV might look like a mere consequence of the WKR problem for the BPC. One can conceive of the buck-passing project as aiming firstly at an explanation of value in terms of correct pro-attitudes, and secondly at an explanation of correctness in terms of reasons. ${ }^{43}$ Accordingly, (BPC)* can be understood as a bridge principle that leads from a fitting attitude analysis (understood in terms of correctness) to (BPV)*, and which creates a WKR problem for all attitudes that have correctness standards. While this understanding of the buck-passing project is not mandatory, proponents of the BPV who do not wish to subscribe to the BPC need to explain why the internal standards of some attitudes (i.e. pro-

\footnotetext{
${ }^{41}$ Cf. Schroeder $(2007,134 ; 2010,40)$.

${ }^{42}$ See note 39 for an important qualification.

${ }^{43} \mathrm{Cf}$. Schroeder $(2010,40)$. This is also how McHugh and Way (2016) seem to understand the BPV, namely as involving the claim that "fittingness" (their preferred term for what we have called correctness) "should be understood in terms of reasons" (576), i.e. as involving the BPC.
} 
attitudes relevant for the BPV) are to be explained in terms of reasons, while other internal standards are not.

We conclude this section with two remarks about the prospects of solving the WKR problem for the BPC. Firstly, solutions that characterize WKR for the BPV in terms of correctness $^{44}$ cannot be employed on behalf of the BPC, on pain of circularity. If one wants to analyze correctness in terms of a particular subset of reasons, then one cannot determine the extension of this set in terms of correctness. Otherwise, "correctness" would feature both in the analysans and the analysandum of the account, thus rendering the analysis circular. In contrast, other proposals from the list introduced above in $\S 1$ might work for both the BPV and the BPC. For example, it seems that we can distinguish between derivative and nonderivative reasons without relying on any judgments about correctness. Thus, characterizing WKR as derivative reasons does not seem to make the BPC circular. Whether non-circular proposals can solve the WKR problem for the BPC depends on how well they can handle WKR for pro-attitudes, beliefs and intentions, but also on whether there are reasons for action that are WKR for the BPC - an issue to which we will turn presently.

Secondly, given that the arguments for skepticism about non-value-related reasons for pro-attitudes are concerned with properties that such reasons arguably share with other nonstandard reasons for attitudes (in particular the property of being incapable of guiding), it comes as no surprise that skeptics of the former kind are usually skeptics about all nonstandard reasons for attitudes. ${ }^{45}$ For all that has been said so far, skepticism about nonstandard reasons for attitudes may well dissolve the WKR problem for both the BPV and the BPC. ${ }^{46}$ As we will explain in the following section, whether the WKR problem for the BPC can eventually be dissolved in this way also crucially depends on whether reasons for action can be WKR for the BPC.

\footnotetext{
${ }^{44}$ See note 20 .

${ }^{45}$ A notable exception is Raz (2011, esp. 56-57), who seems to reject non-standard reasons for emotions and beliefs while holding onto non-standard reasons for intentions. However, it is also difficult to see how Raz's approval of non-standard reasons for intentions is supposed to be compatible with his acceptance of the normative/explanatory nexus (27), esp. given that Raz defines a non-standard reason as a reason that does not satisfy the nexus (40).

${ }^{46}$ For the reasons mentioned above, WKR Skepticism does not by itself meet the challenge of providing a philosophical account of the distinction between standard and non-standard reasons (or standard reasons for attitudes and reasons for e.g. wanting to have such attitudes). But as we have argued, although this explanatory challenge is sometimes also called a "WKR problem", it needs to be distinguished from the WKR problems for the BPV and the BPC.
} 


\section{$\S 3$ Reasons for action}

Some authors maintain that the RKR/WKR distinction can be applied to actions, while others deny this. ${ }^{47}$ Trivially, there cannot be reasons for action that are of the wrong kind for an analysis of value in terms of reasons for attitudes or emotions. ${ }^{48}$ However, there might still be reasons for action that qualify as WKR in either of the two other senses we have identified in §: firstly, the sense in which a WKR is a reason that is of the same general kind as a nonvalue-related reason for a pro-attitude (i.e. a non-standard reason); secondly, the sense in which a WKR is a reason that is unsuitable for the BPC.

Let us start with the question of whether there are reasons for action that share the characteristic features of non-standard reasons for attitudes and can thus be included among the category of non-standard reasons. Here it must be observed that while there are practical reasons that satisfy at least some of Schroeder's earmarks, these seem to fall into two different classes.

On the one hand, the literature contains a number of suggestions for practical reasons that cannot be acted upon and thus satisfy the earmark of motivational asymmetry (and arguably of rational asymmetry as well). For instance, Schroeder has claimed (in a different context) that the fact that there is a surprise party waiting at home can be a reason to go home, even though it is no reason one could ever act upon. ${ }^{49}$ On the other hand, there are reasons for action that satisfy Schroeder's earmark of correctness-insensitivity. This is because some actions are related to practices that have internal standards, and some reasons for such actions are insensitive to such standards. ${ }^{50}$ For example, there are correct or proper ways of baking a cake, tying a knot, playing chess, or dancing a foxtrot, and there are objects that merit certain actions or activities: artworks worthy of protection, questions worthy of discussion, etc. But if a demon threatens you with torture unless you make an incorrect chess move or discuss a question unworthy of being discussed, you seem to have excellent reason to do so. Moreover, such a reason does not seem to be more difficult to act upon than those reasons that matter for the correctness of the acts they favor.

\footnotetext{
${ }^{47}$ See Schroeder (2010, 32-33) and Rabinowicz and Rønnow-Rasmussen (2012a) for the former claim, and Heuer (2011, 170-71 and 179-80) and Hieronymi (2013, 117-18) for the latter.

${ }^{48}$ This is, of course, not to say that it is impossible to analyze value in terms of reasons for action, but this view does not fall under the scope of views that we have here discussed as the BPV (see note 6). Heuer $(2011,178$ 80) suggests that in contrast to accounts that focus on reasons for attitudes, attempts to analyze value in terms of practical reasons are not subject to a WKR problem, due to the fact that there are no WKR for actions. If what we argue in this section is correct, Heuer's suggestion does not stand up to scrutiny.

${ }^{49}$ See Schroeder $(2007,165-66)$.

${ }^{50}$ As Schroeder $(2010,32-33)$ has emphasized.
} 
Both classes of reasons for action just described could be classified as WKR in the sense that they are - in some respect - of the same kind as the reasons for pro-attitudes that are WKR for the BPV. However, since members of each class only bear some of the earmarks that characterize paradigmatic non-standard reasons, it is an open question whether an account of WKR that attempts to explain the difference between standard and non-standard reasons needs to include either class of practical reasons.

In contrast, there can be little doubt that correctness-insensitive reasons for action are plausible candidates for WKR with respect to the project of explaining correctness in terms of reasons. Insofar as practices have internal standards of correctness, and insofar as such standards cannot be analyzed in wholly non-normative terms, a proponent of the reasons-first approach is pressed to analyze them in terms of reasons. Consider again the property of being worthy of discussion. At least prima facie, this looks like a normative property that a proponent of the reasons-first approach is committed to explaining in terms of reasons, and hence it falls into the scope of the BPC. According to the BPC, a question's discussionworthiness depends on the reasons for and against discussing it. But as we have already seen, there seem to be clear counterexamples to unmodified versions of this claim. If a demon threatens you with torture unless you discuss the question of whether the number of hairs on your head is even, this gives you excellent reason to discuss this question, but it is irrelevant to whether the question is worth being discussed. It is hence a WKR for the BPC, over and above those non-standard reasons for attitudes we discussed in $\S 2$.

The fact that there are reasons for actions that are irrelevant to the correctness of these actions has important implications for the WKR problem that the BPC faces. To begin with, it means that at least some proposals for solving the WKR problem for the BPV cannot possibly work as solutions to the WKR problem for the BPC, since they only apply to reasons for attitudes, or are only promising when applied to reasons for attitudes. ${ }^{51}$ This seems clearest in the case of the view that identifies WKR with state-given and RKR with object-given reasons. While the notion of an object has an intuitively clear meaning when applied to attitudes such as desires, admiration, beliefs or intentions (the object being whatever is desired, admired, believed or intended), it is much less clear what the object of an action might be in this sense (it cannot be the thing done, since this just is the action). So it seems that the stategiven/object-given distinction, as usually conceived, has no natural extension to actions.

\footnotetext{
${ }^{51}$ This was pointed out by Schroeder (cf. 2010, 33-36). However, Schroeder's claim that many suggested solutions to the WKR problem for the BPV fail to be fully satisfying due to their lack of sufficient generality seems to presuppose that BPV proponents are committed to the BPC and thus to solving the WKR problem for the BPC, which may be denied.
} 
Other suggested solutions to the WKR problem in turn are applicable to reasons for action, but do not seem to rule out those particular reasons for action that are WKR for the BPC. For example, it seems that at least some correctness-sensitive reasons for action (e.g., a reason for making a certain chess move) derive from other reasons (e.g., a reason to play chess in the first place). If that is so, then an account of the RKR/WKR-distinction in terms of derivative and non-derivative reasons cannot solve the WKR problem for the BPC.

The existence of reasons for action that are of the wrong kind with regard to analyzing correctness also has important implications for the prospects of dissolving the WKR problem for the BPC by embracing WKR Skepticism. Although skepticism about practical reasons that cannot be acted upon can arguably be supported by an argument analogous to the guidance argument against non-standard reasons for attitudes, ${ }^{52}$ skepticism about correctnessinsensitive reasons for action cannot be supported in this way and seems generally a quite implausible position to hold. If you are offered a lot of money to discuss a question that is not worth being discussed, then (other things equal) this seems a perfect reason for doing so. Neither is there any severe difficulty involved in discussing a question for the reason that one has been offered money to do so (talk show hosts do it all the time), nor do any other arguments against non-standard reasons for attitudes favor the denial of such a reason's existence. It therefore seems that the WKR problem for the BPC cannot be dissolved by WKR Skepticism.

\section{$\S 4$ Conclusion and outlook}

We have argued that there are (at least) three ways of understanding the notion of a "reason of the wrong kind" (WKR): first and foremost, as referring to a reason for a pro-attitude or emotion that is unsuitable for the purposes of the buck-passing account of value (BPV); second, as a label for what we have called a "non-standard reason"; and third, as referring to a reason that is unsuitable for the buck-passing account of correctness (BPC). These different understandings also correspond to different WKR problems. We have shown how solutions to these problems are subject to different adequacy conditions, and how the WKR problem for the BPC seems much harder to solve than the WKR problem for the BPV.

For those sympathetic to the BPV, there are different options for dealing with these results. The first is to follow Schroeder in seeking for a unified solution to the WKR problem for both the BPV and the BPC, and to accept the more ambitious task that this involves. The alternative for proponents of the BPV is to reject the BPC. If they do so, they either have to

\footnotetext{
${ }^{52}$ See e.g. Kiesewetter $(2016, \S 3)$.
} 
reject the reasons-first approach to normativity, or they have to demonstrate how internal standards of correctness can be understood in a way that is consistent with this approach, if not along the lines of the buck-passing approach. Finally, the fact that the WKR problem for the BPC is even harder to solve than the original WKR problem for the BPV might also be taken to support the view that standards of correctness are more fundamental than reasons, and that rather than explaining value and correctness in terms of reasons, we should explain value and reasons in terms of correctness. This strategy has recently been defended by McHugh and Way, who call it the "fittingness first" approach. ${ }^{53}$

The possibility of taking correctness to be more fundamental (or at least no less fundamental) than reasons also has implications for the prospects of solving the WKR problem for the BPV. As Schroeder points out, there are reasons to be optimistic that at least some version of the fitting attitude approach is correct for some value properties: the view that for $\mathrm{X}$ to be desirable just is for $\mathrm{X}$ to be worthy of desire can seem hard to resist. ${ }^{54}$ Schroeder concludes from this that "the [WKR] problem is everyone's problem", and that "we should be highly optimistic that whatever the [WKR] problem teaches us, there is at least some solution to be had" ${ }^{55}$ Unless one presupposes that correctness (or worthiness) needs to be analyzed in terms of reasons, however, it is far from clear that an analysis of value in terms of correctness (or worthiness) is vulnerable to anything like a WKR problem. On the face of it, a fitting attitude analysis of value can be vulnerable to a WKR problem only if it employs the notion of a reason, or a notion that is itself to be understood in terms of reasons. It is in principle possible, of course, for an analysis of value in terms of correctness to run into a problem analogous to the WKR problem: a "wrong kind of correctness problem", as it were. ${ }^{56}$ But surely, the existence of such a problem cannot simply be taken for granted. Moreover, anyone who (like Schroeder) accepts both the BPV and the BPC thereby accepts a perfect

\footnotetext{
${ }^{53}$ See McHugh and Way (2016). On McHugh and Way's use of the term "fittingness", see note 4. For an alternative analysis of reasons in terms of correctness (which is, however, limited to reasons for attitudes), see Thomson (2008, Ch. 7).

${ }^{54} \mathrm{Cf}$. Schroeder $(2010,26-27)$. It is arguable, though, that what is actually hard to resist is only the biconditional " $\mathrm{X}$ is desirable iff $\mathrm{X}$ is worthy of desire", and not necessarily the claim that desirability can be analyzed in terms of desire and the worthiness relation. We ignore this here because the difference between a biconditional and an analysis is not relevant for the point that Schroeder aims at.

${ }^{55}$ Schroeder $(2010,27-28)$.

${ }^{56}$ Crisp $(2000,459)$ seems to suggest that a fitting attitude analyses in terms of worthiness is vulnerable to a "wrong kind of worthiness problem", and D'Arms and Jacobson (2000a, 729-32) make analogous points about analyses in terms of appropriateness in their description of the conflation problem (see note 15). Arguably, however, these authors implicitly take for granted that worthiness or appropriateness is to be spelled out in terms of reasons. In contrast, McHugh and Way $(2016,600-2)$ reject the view that fittingness (understood as what we have called correctness, and what others might identify as appropriateness or worthiness) is to be analyzed in terms of reasons, and they argue that their own analysis of value in terms of fittingness is not subject to a "wrong kind of fittingness problem".
} 
correspondence between the relevant value and correctness properties, which rules out the very possibility of a "wrong kind of correctness problem".

None of this entails that fitting attitude analyses in terms of correctness or worthiness are overall preferable, since such analyses might well raise their own problems. It suggests, however, that the WKR problem (as it affects the BPV and the BPC) is not necessarily everyone's problem. It is a problem for analyses that proceed in terms of reasons in particular, and it must be regarded as a serious challenge for such analyses. The WKR problem might have a solution, but it might just as well be a stumbling block to an otherwise promising approach to understanding value, and normativity in general. ${ }^{57}$

\section{References}

Brentano, Franz. 1889. The Origin of Our Knowledge of Right and Wrong, trans. Roderick Chisholm and Elizabeth Schneewind, London: Routledge (2009).

Broome, John. 2004. "Reasons." In Reason and Value. Themes from the Moral Philosophy of Joseph Raz, edited by R. Jay Wallace, Philip Pettit, Samuel Scheffler, and Michael Smith, 28-55. Oxford: Oxford University Press.

Crisp, Roger. 2000. "Review of 'Value ... And What Follows' By Joel Kupperman". Philosophy 03: 452-62.

Danielsson, Sven, and Olson, Jonas. 2007. "Brentano and the Buck-Passers". Mind 116 (463): 511-22.

D’Arms, Justin and Jacobson, Daniel. 2000a. "Sentiment and Value". Ethics 110: 722-48.

—. 2000b. "The Moralistic Fallacy. On the 'Appropriateness' of Emotions". Philosophy and Phenomenological Research 61 (1): 65-90.

- 2014. "Wrong Kinds of Reason and the Opacity of Normative Force". Oxford Studies in Metaethics 9: 215-44.

Darwall, Stephen. 2002. Welfare and Rational Care. Princeton: Princeton University Press.

Geach, Peter. 1956. "Good and Evil". Analysis 17: 32-42.

Gibbard, Allan. 1990. Wise Choices, Apt Feelings. A Theory of Normative Judgment. Oxford: Clarendon Paperbacks.

Gregory, Alex. 2014. "A Very Good Reason to Reject the Buck-Passing Account". Australasian Journal of Philosophy 92 (2): 287-303.

Heuer, Ulrike. 2011. "Beyond Wrong Reasons: The Buck-Passing Account of Value". In New Waves in Metaethics, ed. Michael Brady, 166-84. Palgrave Macmillan.

Hieronymi, Pamela. 2005. "The Wrong Kind of Reason”. The Journal of Philosophy 102 (9): $437-57$.

- 2013. "The Use of Reasons in Thought (and the Use of Earmarks in Arguments)". Ethics 124: 114-27.

Howard, Christopher. 2016. "In Defense of the Wrong Kind of Reason”. Thought 5: 53-62.

\footnotetext{
${ }^{57}$ For very helpful comments on earlier versions of this paper, we would like to thank Alex Gregory, Toni Rønnow-Rasmussen, Pekka Väyrynen, an anonymous referee, the participants of Thomas Schmidt's research colloquium at Humboldt University of Berlin, as well as the participants of the conference "The Wrong Kind of Reasons", which took place in September 2014 at Humboldt University of Berlin. Work on this paper has been supported by the Deutsche Forschungsgemeinschaft (DFG project "Principles of the Deliberative Ought") and the Einstein Foundation Berlin.
} 
Jacobson, Daniel. 2013. "Wrong Kind of Reasons Problem”. International Encyclopedia of Ethics, edited by Hugh LaFollette. Chichester: Blackwell.

James, William. 1896. "The Will to Believe". Reprinted in The Will to Believe and Other Essays in Popular Philosophy, 1-31. New York: Dover (1956).

Kavka, Gregory S. 1983. "The Toxin Puzzle". Analysis 43 (1): 33-36.

Kelly, Thomas. 2002. "The Rationality of Belief and Some Other Propositional Attitudes". Philosophical Studies 90: 163-96.

Kiesewetter, Benjamin. 2016. "You Ought to $\Phi$ Only If You May Believe that You Ought to $\Phi ”$. The Philosophical Quarterly 66 (265): 760-82.

- "How Reasons Are Sensitive to Available Evidence". In Normativity: Epistemic and Practical, edited by Conor McHugh, Jonathan Way, and Daniel Whiting, forthcoming with Oxford University Press.

Lang, Gerald. 2008. "The Right Kind of Solution to the Wrong Kind of Reason Problem". Utilitas 20 (4): 472-89.

Louise, Jennie. 2009. "Correct Responses and the Priority of the Normative". Ethical Theory and Moral Practice 12: 345-64.

McHugh, Conor and Way, Jonathan. 2016. "Fittingness First". Ethics 126 (3): 575-606.

Olson, Jonas. 2004. "Buck-Passing and the Wrong Kind of Reasons". The Philosophical Quarterly 54: 295-300.

. 2009. "The Wrong Kind of Solution to the Wrong Kind of Reason Problem". Utilitas 21: $225-32$.

Parfit, Derek. 2001. "Rationality and Reasons". In Exploring Practical Philosophy: From Action to Values, ed. Dan Egonsson, Jonas Josefsson, Björn Petersson, and Tonio Rønnow-Rasmussen, 17-39. Aldershot: Ashgate.

- 2011. On What Matters. Oxford: Oxford University Press.

Persson, Ingmar. 2007. "Primary and Secondary Reasons". In Hommage á Wlodek: Philosophical Papers Dedicated to Wlodek Rabinowicz, edited by Toni RønnowRasmussen et al. URL: http://www.fil.lu.se/hommageawlodek.

Piller, Christian. 2006. "Content-Related and Attitude-Related Reasons for Preferences". Royal Institute of Philosophy Supplements 81 (59): 155-81.

Rabinowicz, Wlodek, and Rønnow-Rasmussen, Toni. 2004. "The Strike of the Demon: On Fitting Pro-Attitudes and Value". Ethics 114 (3): 391-423.

. 2006. "Buck-Passing and the Right Kind of Reasons". The Philosophical Quarterly 56 (222): 114-20.

- 2012a. "Ethics Discussion at PEA Soup: Rabinowicz and Rønnow-Rasmussen on Way". PEA Soup Blog. URL: http://peasoup.typepad.com/peasoup/2012/06/ethicsdiscussions-at-pea-soup-rabinowicz-and-ronnow-rasmussen-on-way.html.

.2012b. "Ethics Discussion at PEA Soup: Rabinowicz and Rønnow-Rasmussen on Schroeder". PEA Soup Blog. URL: http://peasoup.typepad.com/peasoup/2012/06/i.html.

Raz, Joseph. 2011. From Normativity to Responsibility. Oxford: Oxford University Press.

Reisner, Andrew. 2009. "The Possibility of Pragmatic Reasons for Belief and the Wrong Kind of Reasons Problem". Philosophical Studies 145 (2): 257-72.

Rønnow-Rasmussen, Toni. 2011. Personal Value. Oxford: Oxford University Press.

Rowland, Richard. 2013. "Wrong Kind of Reasons and Consequences". Utilitas 25 (3): 40516.

. 2015. "Dissolving the Wrong Kind of Reason Problem". Philosophical Studies 172 (6): $1455-74$.

- 2016. "Reasons as the Unity among the Varieties of Goodness". Pacific Philosophical Quarterly 97: 200-27.

Samuelsson, Lars. 2013. "The Right Version of 'the Right Kind of Solution to the Wrong Kind of Reason Problem". Utilitas 25 (3): 383-404. 
Scanlon, Thomas M. 1998. What We Owe to Each Other. Cambridge, MA: Harvard University Press.

Schroeder, Mark. 2007. Slaves of the Passions. Oxford: Oxford University Press.

- 2010. "Value and the Right Kind of Reason". Oxford Studies in Metaethics 5: 25-55.

- 2012. "The Ubiquity of State-Given Reasons". Ethics 122 (3): 457-88.

- 2013. "State-Given Reasons: Prevalent, If Not Ubiquitous". Ethics 124: 128-40.

Sharadin, Nathaniel. 2015. "Reasons Wrong and Right". Pacific Philosophical Quarterly 97: 371-99.

Skorupski, John. 2007. "Buck-Passing about Goodness". In Hommage á Wlodek: Philosophical Papers Dedicated to Wlodek Rabinowicz, edited by Toni RønnowRasmussen et al. URL: http://www.fil.lu.se/hommageawlodek.

. 2010. The Domain of Reasons. Oxford: Oxford University Press.

Smith, Michael. 1994. The Moral Problem. Oxford: Blackwell.

Stratton-Lake, Philip. 2005. "How to Deal with Evil Demons: Comment on Rabinowicz and Rønnow-Rasmussen”. Ethics 115 (4): 788-98.

Suikkanen, Jussi. 2009. "Buck-Passing Accounts of Value”. Philosophy Compass 4 (5): 768 79.

Thomson, Judith Jarvis. 2008. Normativity. Chicago and La Salle: Open Court.

Way, Jonathan. 2012. "Transmission and the Wrong Kind of Reason”. Ethics 122 (3): 489515.

Williams, Bernard. 1979. “Internal and External Reasons”. Reprinted in Moral Luck, 101-13. Cambridge: Cambridge University Press (1981). 